
and Deborah Fenney Salkeld

\title{
16 Influence of Environmental Factors on Play for Children with Disabilities - An Overview
}

\subsection{Introduction}

This chapter considers the impact of the environment on the play experience of disabled children or children with disabilities. The International Classification of Functioning (ICF) defines 'environment' as "social attitudes, architectural features, legal and social structures, as well as climate, terrain and so forth” (WHO 2002:10). Whilst this is a helpful opening definition of 'environment', for the purpose of this chapter, we adopt the following elaboration of the concept of social environment, which, we argue, is in keeping with the WHO's definition:

"the immediate physical surroundings, social relationships, and cultural milieus within which defined groups of people function and interact. Components (...) include built infrastructure; (...) social and economic processes; wealth; social, human, and health services; power relations; government; (...) social inequality; cultural practices; the arts; religious institutions and practices; and beliefs about place and community. The social environment subsumes many aspects of the physical environment, given that contemporary landscapes (...) and other natural resources have been at least partially configured by human social processes" (Barnett \& Casper, 2001:465).

As stated in the preamble to the United Nation Convention on the Rights of Persons with Disabilities (UNCRPD, 2007, para. e), disability 'results from the interaction between persons with impairments and attitudinal and environmental barriers that hinder their full and effective participation in society on an equal basis with others'. Whilst the language of the UNCRPD may differ slightly from that of the ICF, the ICF model shares this understanding of disability. Environmental factors are understood to operate as barriers or facilitators of people with disabilities; to be enabling or constraining.

In this chapter, we focus on the constraining-or disabling-aspects of the environment on the play experiences and opportunities of children with disabilities. This is not because we fail to recognise that there are examples of good practice 'out there', where children with disabilities have been empowered in their play. Such examples exist and are to be celebrated. They are, however, the exception rather than the rule.

Taking the UK as an example, the findings of a recent UK Public Inquiry by the Charity Sense, chaired by Lord Blunkett and Lesley Rogers, are revealing. The 
inquiry exposed many environmental factors acting as barriers to play for children with multiple disabilities. The inquiry found that amongst parents of children with disabilities interviewed, 81\% reported difficulties in accessing the mainstream play groups and local play opportunities for their child. Many said that they had experienced negative attitudes towards their child, and that this was the most significant barrier to accessing the mainstream play settings. Fifty-one percent of the parents said their child had been intentionally excluded from play opportunities by providers of play. Forty percent said that they faced additional financial costs when seeking to access play opportunities. Many of the families consulted said there was a lack of specialist support that could be accessed locally and were having to make long journeys to access play settings. The inquiry also found that: many play settings were not accessible to children with multiple needs; few settings had been designed to welcome and support parents and non-disabled siblings, so that they could play together with a child with disabilities; levels of awareness and relevant training in medical conditions, communication methods, and multiple disabilities by play professionals act as barriers to children accessing play provision; misguided notions of 'health and safety' can result in children with disabilities, sometimes being denied the right to play (Sense, 2016). Further, in June 2016, the advanced, unedited version of the UNCRC Committee on the Rights of the Child's 'Concluding observations on the fifth periodic report of the United Kingdom of Great Britain and Northern Ireland' highlighted insufficient places and facilities for play and leisure for children in the UK, in particular those accessible for children with disabilities (our emphasis). We suspect that the situation in the UK would resonate with many countries across Europe and beyond.

Our emphasis on barriers-disabling barriers-is a reflection of our adoption within this chapter of perspectives from interdisciplinary Disability Studies. Disability Studies have challenged the traditional approaches to childhood disability. In 1998, a leading author in this field, Mark Priestley, proposed an agenda for research in this area. Research at that time, he argued, had become "preoccupied with impairment, vulnerability and service usage" and needed to recognise children with disabilities as "social actors, negotiating complex identities within a disabling environment" (Priestley, 1998:207, our emphasis). Research, he stated, needed to be informed by new Disability Studies approaches to understanding disability. This new approach represented a sustained critique of the 'individual model' of disability (Oliver, 1990) and versions of this-that is, 'medical' and 'personal tragedy' models-which view disability as a personal predicament. Whilst not denying the existence or impact of impairments, this approach, which has come to characterise the approach taken by many/most academics in Disability Studies, considers the 'problem' of disability to reside within society, not within individual minds or bodies. From a Disability Studies perspective, disability is a form of social oppression, not simply restricted activity (however, caused) and results from actions on the part of the non-disabled majority. These actions-through social structures, organisations, professional practice, and 
interpersonal interaction-impact negatively on the lives of people with disabilities. Disability is a social relational category-an effect and quality of relationships of power and exclusion between groups in our societies (Thomas, 2004). This approach, thus, involved a paradigm shift. Disability became understood as a social rather than an individual pathology (Goodley, 2014); a public issue, not simply a personal trouble (Borsay, 1986).

Allied as it is to the disabled people's movement and their politicisation of 'disability', Disability Studies have long worked to expose environmental factors that act as barriers in the lives of people with disabilities, seeing this as the first step towards challenging and dismantling these barriers. In this chapter, we take such an approach. We identify a range of environmental barriers that 'disable' play for children with disabilities, and by doing so, propose avenues for developing enabling play environments for these children. Although in practice, many of these barriers are inter-related, for the purposes of this chapter, we distinguish different broad barrier types-physical, social, political, and cultural-occurring in a selection of social situations or locations-built environment, educational settings, home, and natural environments. These locations can also overlap (e.g., in the case of home schooling or nature playgrounds in school settings). We distinguish them only to point to issues that may be experienced differently in particular locations and to suggest specific avenues for further research.

\subsection{Barriers to Play for Children with Disabilities within Four Key Contexts}

General Comment 17 on the UNCRC stresses that children with disabilities encounter 'multiple barriers' in relation to the rights provided in Article 31, including exclusion from social situations, where play takes place and friendships can be formed, isolation, cultural attitudes, and stereotypes, physical inaccessibility, and exclusionary or ineffective policies. Before considering some of these barriers manifesting within our four key location types, we highlight the importance of certain political and cultural barriers impacting across these locations. First, political barriers: play for children with disabilities is not always given sufficient attention by policy makers. At a global level, both the UNCRC (Article 31) and the UNCRPD (Article 30) enshrine the right of children with disabilities to play and leisure or recreation. Two General Comments on articles of the UNCRC, however, have highlighted the key difficulties in protecting and upholding these rights. In Europe, despite universal ratification of the UNCRC, different states have progressed at different rates with regard to acknowledging and properly resourcing play provision for children with disabilities (Barron et al., forthcoming). There is a slippage between the ambitions set out within the international conventions and their operation in relation to national legislation, policy, and practice. Further 
research needs to establish how different states in Europe are developing policies promoting inclusive play and monitoring their effectiveness.

In terms of cultural barriers, although studies indicate that children with disabilities enjoy similar activities to their non-disabled peers (Engel-Yeger et al., 2009; Hilton et al., 2008; Imms et al., 2008), play is often positioned or understood differently for them. Problematic discourses of play exist and have real effects (Joseph \& Roberts, 2007) in terms of the exclusion of children with disabilities. These children are more likely to be considered 'deficient' in the abilities necessary for play, and consequently, to be subject to greater adult intervention and surveillance in their play activities, reducing their opportunities for free play (Goodley \& Runswick-Cole, 2010). Their play, as for many children, but perhaps more acutely in the case of children with disabilities, is also more likely to be subject to the "play as progress" rhetoric, which involves the "subordination of intrinsic play functions to other extrinsic developmental functions” (Sutton-Smith, 1997: 18). This means that children with disabilities risk missing out on experiencing play for its own sake and its associated benefits.

We now turn to additional and specific barriers identified within our four key locations. In what follows, we draw upon a narrative review of the existing international research into barriers to play for children with disabilities undertaken by the authors for the LUDI network and which is considered in depth within Barron et al. (forthcoming).

\subsubsection{Barriers in the Built Environment}

A 'built environment' refers to the human-made space in which a human activity takes place. For children playing, such spaces might include playgrounds, parks, and other community play spaces. The outdoor public playground (Moore \& Lynch, 2015; Webb, 2003) has been the main focus of research into play for children with disabilities within built environments. Evidence suggests that these children encounter physical barriers and are less playful where there is inadequate design-that is, when those designing and providing play spaces have insufficient knowledge about disability and universal design (Dunn \& Moore, 2005; Prellwitz \& Tamm, 1999; Rigby \& Gaik, 2007; Woolley, 2013). Physical access to play spaces is an essential prerequisite to play for children with disabilities.

The absence of or inaccessibility of play resources or materials is also important, as are other issues that may create barriers within play spaces: noise, over-crowding, temperature, unsuitable lighting, design, inaccessible surfaces, etc., depending on the needs of individual children (Law et al., 1999; Rimmer et al., 2004). Finding solutions to these barriers can be challenging, however, because 'special' accessible features in playgrounds (as opposed to fully integrated accessibility) can also lead to segregation (Dunn \& Moore, 2005). 
Inaccessible built environments and the resulting lack of interaction between children with and without disabilities can reinforce attitudinal barriers (Atmakur, 2013). Exclusion of children with disabilities by non-disabled peers within this type of location (e.g., playgrounds) is as yet under-researched, but on the basis of existing evidence about children's experiences of play in a variety of contexts, this is likely to be a significant problem. Children with disabilities have reported that they are not asked to play by other children or that they have been told that they are not welcome to join in games (Spencer-Cavaliere \& Watkinson, 2010). Children with disabilities may also self-exclude through fear of being seen to use play equipment in the 'wrong way', and so, wait until playgrounds are empty before using it (Prellwitz \& Skar, 2007). Alternatively, it may be necessary for parents to be present in play situations, for example, to provide assistance to move around and use playground equipment where the design of the playground does not support the child's independent mobility (Prellwitz \& Skar, 2007). Children have indicated that they would prefer to use playgrounds independently. Parental anxieties about stigma felt by their children in such situations has led some families to avoid playgrounds (Prellwitz, 2007).

\subsubsection{Barriers in Educational Settings}

Educational settings may be formal (e.g., kindergarten, primary and secondary school classrooms) or informal (e.g., school playgrounds and after-school clubs). Such settings should provide a safe environment for children's development, foster active learning, and encourage positive peer relations (Moyles, 2013).

Evidence suggests that physical barriers exist within school buildings in some countries (Santer et al., 2007), reflecting the historic exclusion of children with disabilities from education, or from 'mainstream' education. Accessibility for these children within school playgrounds is not always considered (Rigby \& Gaik, 2007), leading them to encounter similar difficulties to those in other outdoor play settings (as aforementioned). Attitudinal barriers are also present within this type of environment. Exclusion by peers has been reported by children with disabilities and can occur during recess, for example (Spencer-Cavaliere \& Watkinson, 2010; Taub \& Greer, 2000).

One way educational settings differ from wider built or natural environment settings is that teachers and other education professionals are often present. Evidence suggests that the attitude and behaviour of teachers can play a significant role in relation to play for children with disabilities. Teachers initiate and facilitate play between children with and without disabilities through modelling appropriate behaviour and supervising play (Odom et al., 1993, 1996). Alternatively, however, they sometimes create barriers by not supporting children with disabilities to engage in a wide and varied range of play activities (Ozen et al., 2013) or by limiting opportunities to make choices, take risks, embrace challenges, and make friends (Richardson 2002). 
Educational professionals without appropriate levels of knowledge and sensitivity may also deny the opportunity for play through the educational policy that they deliver (Buchanon \& Johnson, 2009; Richardson, 2002).

\subsubsection{Barriers at Home}

'Home' is a contested concept associated with a range of meanings and environments. Most importantly, 'home' is what each individual understands it to be. For children with disabilities, home may refer to the private family, but also to diverse care settings (e.g., hospitals or orphanages). Home may be a space supporting playfulness, when compared to other settings, particularly as the child ages (Law et al., 2007; Rigby \& Gaik, 2007). Nevertheless, evidence suggests that barriers exist here.

Evidence of physical barriers include children with disabilities requiring assistance transferring between play spaces (e.g., up or down stairs), lack of space to manoeuvre wheelchairs, or so much space being taken up by assistive technologies and other equipment that accommodating visits from friends becomes difficult (Brotherson et al., 2008; Connors \& Stalker 2003; Geisthardt et al., 2002). Additionally, attitudinal barriers manifest within home. Parents can be highly supportive of their child's play, but evidence suggests that some struggle to come to terms with their child's impairment and delay making physical adaptations to the home that would remove physical barriers to play (Lewis, 1987). Peers' attitudes may mean that children with disabilities are not always invited to friends' homes to play; equally, they may not be encouraged or supported to invite friends to come to their homes to play (Mundhenke et al., 2010; Sandberg et al., 2004). Parents' perceptions of risk may be important here: some parents have been found to restrict play in the home or not allow friends to visit for play due to perceptions of 'risk' (Connors \& Stalker, 2003). Additionally, this may reflect concerns of parents regarding bullying and difficulties that non-disabled children may have knowing how to play with their children (Oates et al., 2011; Preece \& Jordan, 2009). Barriers to play in the home may then reinforce barriers in other settings: research has shown that children with ASD, who have fewer playdates organised for them in the home, find engaging in play with peers in the school playground more difficult (Frankel et al., 2011).

\subsubsection{Barriers in the Natural Environment}

Identifying entirely natural settings in our world is challenging. There are few untouched wildernesses today (Cronon, 1996). Most natural environments that children encounter will be to some extent managed or modified by humans (Lester \& Maudsley, 2007). Nevertheless, many authors agree that 'natural' spaces exhibit fewer elements of human design than 'built' environments. The value of play in the 
natural environment has been given increasing attention recently. Concerns about a 'couch potato' generation of children glued to electronic media (Hancox, 2004) and a 'bubble-wrap' generation of children whose parents are too anxious to let them play outside (Malone, 2007) are associated with increased valuing and promotion of play in nature (Louv, 2005).

Several studies have emphasised the benefits of playing in and with nature for children with and without disabilities (Blakesley et al., 2013; Pavey 2006; Kuo \& Faber Taylor, 2004). As noted earlier, however, the primary focus of studies considering access to outdoor play for children with disabilities has been primarily on built environments such as playgrounds (e.g., Moore \& Lynch, 2015; Webb, 2003). The right of access to nature for all children-a right referenced in the UNCRC-has often been forgotten (Anderson-Brolin, 2002). Whilst various reports (for organisations such as Play England and Barnados) highlight the importance of accessibility visa-vis, natural environments for children with disabilities and cite examples of good practice (Shackell et al., 2008; Lester \& Maudsley, 2007), their overall message is that accessibility and inclusion are currently the exception rather than the rule.

Little research has been undertaken that explores barriers to play within natural environments for children with disabilities. Nevertheless, there is evidence of a range of barriers faced by all people with disabilities when seeking to access the natural environment, which would be worthy of further exploration vis-a-vis the experiences of children with disabilities, in particular. Barriers include insufficient information about physical accessibility, inadequate personal and private transport, inaccessible facilities, and staff attitudes at sites (Burns et al., 2008; Countryside Agency, 2005; Williams et al., 2004). Attitudes held by some professionals and parents can also be a significant barrier to 'nature play' for children with disabilities. For example, staff at outdoor recreation sites have been found to view outdoor, less-supervised activities to be 'too risky' for children with disabilities (Gleave, 2010). Similarly, Ludvigsen et al. (2005) found that some parents of children with disabilities, although initially positive about the idea of adventure play, perceived play sites to be 'unsafe'. Children with disabilities have indicated that such 'over-protection' limits opportunities for creativity, risk-taking, and physical challenge, all key factors in play (Andrews, 2012).

\subsection{Discussion}

This chapter considers the ways in which the social environment may limit the opportunities for play for children with disabilities, but is not an exhaustive consideration of this issue. We highlight, for example, the absence of consideration within the current research of socio-economic factors that may impact on play for children with disabilities. Economic barriers are likely to require further investigation, alongside wider environmental factors that may indirectly or directly affect access to play for these children-for example, the intersection of disability with other social 
and cultural factors relating to gender or ethnicity. The interaction of diverse sociodemographic characteristics deserves further attention.

Adults (teachers, parents, and other professionals) clearly have a key role in relation to facilitating play for children with disabilities. The tensions noted in educational settings and built environments between facilitating inclusion and limiting self-determination, as well as the barriers that may be created by the disabling attitudes of adults, require further research to identify strategies that can overcome these attitudes and balance adult facilitation with child-directed play.

In relation to unequal play opportunities for children with disabilities, the barriers created by impairments themselves must not be forgotten, but it is vitally important to recognise that any intervention at the individual level needs to be considered in relation to the environmental factors. Only by addressing disabling barriers external to the minds and bodies of individual children can we address the disablism, which disadvantages them, and remove obstacles to their right to play.

Finally, we suggest a framework for researching environmental barriers to play for children with disabilities. It is important to view the social environment encountered by children from the most immediate and personal through to the broadest social or societal. Various dimensions of a child's social environment might be examined, as follows (adapted from Brown, 2001):

- Accessibility: can children go where they would like to go? Are they fully included? Can they do what they would like to do?

- Resourcing: are their needs being met in ways that enable their play?

- Social support or enablement: are they welcomed and supported by those around them (peers and others)?

- Equality: are they treated equally compared with other children? Are they receiving equal opportunities for play?

The purpose of this list is not to rank different types of locations, but rather to understand the different types of interaction that individuals have with the environmental factors in given locations. It provides ideas about the types of intervention that might ensure that environmental factors become facilitators, not barriers to play for children with disabilities.

\section{References}

Anderson-Brolin, L. (2002). The Rights of the Child and the Physical Environment - The UN Convention on the Rights of the Child and other Relevant International Agreements [report].

Retrieved from: http://resourcecentre.savethechildren.se/sites/default/files/documents/2419. pdf.

Andrews, M. (2012). Exploring Play for early Childhood Studies. London, UK: Sage.

Atmakur, S. (2013). Focus: Playgrounds of exclusion. Retrieved from: http://www.unicef.org/ sowc(2013)/focus_playgrounds_of_inclusion.html. 
Barnes, C., \& Mercer, G. (2010). Exploring Disability: a Sociological Introduction (2 $2^{\text {nd }}$ ed.). Cambridge, UK: Polity.

Barnett, E., \& Casper, M. (2001). A definition of "social environment". [Letter to the editor]. American Journal of Public Health, 91, 465.

Barron, C., Beckett, A. E., Cannon-Jones, N., Coussens, M., Desoete, A., Fenney, D., Lynch, H., \& Prellwitz, M. (Forthcoming). Barriers to Play and Recreation for Children with Disabilities. Berlin, D: De Gruyter.

Beckett, A. E., \& Campbell, T. (2015). The social model of disability as an oppositional device. Disability and Society, 30, 270-283.

Bickenback, J. E. (2012). The International Classification of Functioning, Disability and Health and its relationship to disability studies. In N. Watson, A. Roulstone, \& C. Thomas (Eds.), Routledge Handbook of Disability Studies (pp. 51-66). Abingdon, UK: Routledge.

Blakesley, D., Rickinson, M., \& Dillon, J. (2013). Engaging Children on the Autistic Spectrum with the Natural environment: Teacher insight study and evidence review (Natural England Commissioned Report NECR 116). London, UK: Natural England.

Borsay, A. (1986). Personal Trouble or Public Issue? Towards a Model of Policy for People with Physical and Mental Disabilities. Disability, Handicap and Society, 1, 179-195.

Brotherson, M. J., Cook, C. C., Erwin, E. J., \& Weigel, C. J. (2008). Understanding self-determination and families of young children with disabilities in home environments. Journal of Early Intervention, 31, 22-43.

Brown, S. C. (2001). Methodological Paradigms That Shape Disability Research. In G. L. Albrecht, K. D. Seelman, \& M. Bury (Eds.), Handbook of Disability Studies (pp. 145-170). London, UK: Sage.

Buchanon, M., \& Johnson, T. G. (2009). A Second look at play for Young Children with Disabilities. American Journal of Play, 2, 41-59.

Burns, N., Paterson, K., \& Watson, N. (2008). Exploring Disabled People's Perceptions and Use of Forest Recreation Goods, Facilities and Services in Scotland, England and Wales [report]. Strathclyde Centre for Disability Research, UK. Retrieved from: http://www.forestry.gov.uk/ pdf/SCDR_2008_Disabled_perceptions_and_woodland.pdf/\$FILE/SCDR_2008_Disabled_ perceptions_and_woodland.pdf.

Connors, C., \& Stalker, K. (2003). The Views and Experiences of Disabled Children and Their Siblings: A Positive Outlook. London, UK: Jessica Kingsley Publishers.

Countryside Agency. (2005). “WHAT ABOUT US?” Diversity Review evidence-part one. [report]. Retrieved from:

http://www.naturalengland.org.uk/ourwork/enjoying/outdoorsforall/diversityreview/ publications/default.aspx.

Cronon, W. (1996). The trouble with wilderness: or, getting back to the wrong nature. Environmental History, 1, 7-28.

Dunn, K., \& Moore, M. (2005). Developing accessible play space in the UK: a social model approach. Children, Youth and Environments, 15, 331-354.

Engel-Yeger, B., Jams, T., Anaby, D., \& Law, M. (2009). Differences in patterns of participation between youths with cerebral palsy and typically developing peers. American Journal of Occupational Therapy, 63, 96-104.

Frankel, F., Gorospe, C., Chang, Y., \& Sugar, C. (2011). Mothers' reports of play dates and observation of school playground behaviour of children having high-functioning autism spectrum disorders. Journal of Child Psychology and Psychiatry, 52, 571-579.

Geisthardt, C. L., Brotherson, M., Cook, \& Christine, C. (2002). Friendships of Children with Disabilities in the Home Environment. Education and Training in Mental Retardation and Developmental Disabilities, 37, 235-52. 
Gleave, J. (2010). Making it Our Place: Community Views on Children's Play. London, UK: Play England. Retrieved from: http://socialwelfare.bl.uk/subject-areas/services-client-groups/ children-young-people/playengland/making10.aspx.

Goodley, D. (2014). Dis/ability Studies-Theorising Disablism and Ableism. Oxon: Routledge.

Goodley, D., \& Runswick-Cole, C. (2010). Emancipating play: dis/abled children, development and deconstruction. Disability and Society, 25, 499-512.

Gustavsson, A., Tøssebro, J., \& R. Traustadóttir (2005). Introduction: Approaches and perspectives in Nordic disability research. In A. Gustavsson, J. Sandvin, R. Traustadóttir, \& J. Tøssebro (Eds.), Resistance, Reflection and Change: Nordic Disability Research (pp. 23-44). Lund, S: Student literature.

Hancox, B. (2005). Growing 'couch potatoes': television, computers and childhood obesity as a response to Gard (2004). Children's Issues: Journal of the Children's Issues Centre, 9, 32-36.

Hilton, C. L., Crouch, M. C., \& Israel, H. (2008). Out-of-school participation patterns in children with high-functioning autism spectrum disorders. American Journal of Occupational Therapy, 62, 554-563.

Hurst, R. (2000). To revise or not to revise? Disability and Society, 15, 1083-1087.

Imms, C. (2008). Children with Cerebral Palsy Participate: A Review of the Literature. Disability and Rehabilitation, 30, 1867-1884.

Joseph, J., \& Roberts, J.M. (2004) Introduction: realism, discourse and deconstruction. In: J. Joseph \& J. M. Roberts (Eds.), Realism, discourse and deconstruction (pp.1-20). London, UK: Routledge.

Kuo, F., \& Faber Taylor, A. (2004). A potential natural treatment for Attention-Deficit Hyperactivity disorder: evidence from a national study. American Journal of Public Health, 94, 1580-1586.

Law, M., Haight, M., Milroy, B., Williams, D., Stewart, D., \& Rosenbaum, P. (1999). Environmental factors affecting the occupations of children with physical disabilities. Journal of Occupational Science, 6, 102-110.

Law, M. Petrenchik, T., King, G., \& Hurley, P. (2007). Perceived environmental barriers to recreational, community, and school participation for children and youth with physical disabilities. Archives of Physical Medicine and Rehabilitation, 88, 1636-1642.

Lester, S., \& Maudsley, M. (2007). Play naturally: a review of children's natural play. London, UK: National Children's Bureau and Play England.

Lewis, B. (1987). How are families managing at home? Architectural barriers in households of children with special needs- an issue ignored by health professional. Children's Environments Quarterly, 4, 36-41.

Louv, R. (2005). Last Child in the Woods: Saving our Children from Nature-Deficit Disorder. London, UK: Atlantic Books.

Ludvigsen, A., Creegan, C., \& Mills, H. (2005). Let's Play Together: Play and Inclusion. Evaluation of Better Play Round Three [report]. Retrieved from: www.barnardos.org.uk/lets_play_together_ report.pdf.

Malone, K. (2007). The bubble-wrap generation: children growing up in walled gardens. Environmental Education Research, 13, 513-527.

McLaughlin, J. (2006). Conceptualising Intensive Caring Activities: the Changing Lives of Families with Young Disabled Children. Sociological Research Online, 11.

Moore, A., \& Lynch, H. (2015). Accessibility and usability of playground environments for children under 12: A scoping review. Scandinavian Journal of Occupational Therapy, 22, 331-334.

Moyles, J. (2013). Play and Early Years [webpage]. Retrieved from: http://www.playwales.org.

Mundhenke, L., Hermansson, L., \& Nattterland, B. (2010). Experiences of Swedish children with disabilities: activities and social support in daily life. Scandinavian Journal of Occupational Therapy, 17, 130-139.

Nilsen, R. D., \& Rogers, B. (2005). “That's not a good idea, mom": Negotiating children's subjectivity while constructing 'home' as a research site. Children's Geographies, 3, 345-362. 
Oates, A., Bebbington, A., Bourke, J., Girdler, S., \& Leonard, H. (2011). Leisure participation for school-aged children with Down syndrome. Disability and Rehabilitation, 33, 1880-1889.

Odom, S. L., Peck, C. A., Hanson, M., Beckman, P. J., Kaiser, A. P., Lieber, J., ... \& Schwartz, I. S. (1996). Inclusion at the preschool level: An ecological systems analysis. Social Policy: Society for Research on Child Development, 10, 18-30.

Oliver, M. (1990). The Politics of Disablement. Basingstoke, UK: The Macmillan Press Ltd.

Oliver, M., \& Barnes, C. (2011) The New Politics of Disablement. Tavistock, UK: Palgrave.

Ozen, A., Ergonekon, Y., Ulke-Kurkcuoglu, B., \& Genç, D. (2013). Opinions of special education teachers about activity-based intervention. H.U. Journal of Education, 44, 262-274.

Pavey, B. (2005). The Forest School and Inclusion: a Project evaluation [report]. University of Leeds. Retrieved from: http://www.leeds.ac.uk/educol/documents/161165.doc.

Preece, D., \& Jordan, R. (2010) Obtaining the views of children and young people with autism spectrum disorders about their experience of daily life and social care support. British Journal of Learning Disabilities, 38, 1354-4187.

Prellwitz, M. (2007). Playground accessibility and usability for children with disabilities. PhD thesis: Lulea University of Technology, Sweden.

Prellwitz, M., \& Skar, L. (2007). Usability of playgrounds for children with different abilities. Occupational Therapy International, 14, 144-155.

Prellwitz, M. \& Tamm, M. (1999). Attitudes of key persons to accessibility problems in playgrounds for children with restricted mobility: A study in a medium-sized municipality in northern Sweden. Scandinavian Journal of Occupational Therapy, 6, 166-173.

Priestley, M. (1998). Childhood disability and disabled childhoods. Agendas for research. Childhood, 5, 207-223.

Richardson, P. K. (2002). The School as Social Context: Social Interaction. Patterns of Children with Physical Disabilities. American Journal of Occupational Therapy, 56, 296-304.

Rigby, P., \& Gaik, S. (2007). Stability of Playfulness Across Environmental Settings. A Pilot Study. Physical and Occupational Therapy in Paediatrics, 27, 27-43.

Rimmer, J. H., Riley B., Wang, E., Rauworth, A., \& Jurkowski, J. (2004). Physical activity participation among persons with disabilities: barriers and facilitators. American Journal of Preventive Medicine, 26, 419-25.

Sandberg, A., Bjorck-Akesson, E., \& Granlund, M. (2004). Play in retrospection: play experiences from childhood in adults with visual disability, motor disability and Asperger syndrome. Scandinavian Journal of Disability Research, 6, 111-130.

Santer, J., Griffiths, C., \& Goodall, D. (2007). Free Play in Early Childhood [report]. London, UK. Play England. Retrieved from: http://www.playengland.org.uk/media/120426/free-play-in-earlychildhood.pdf.

Sense (2016). Making the case for play. Findings of the Sense Public Inquiry into Access to Play Opportunities for Disabled Children with Multiple Needs [report]. London, UK: Sense. Retrieved from https://www.sense.org.uk/sites/default/files/the-case-for-play-report.pdf.

Shackell, A., Butler, N., Doyle, P., \& Ball, D. (2008). Design for Play: A Guide to Creating Successful Play Spaces [report]. Play England. Retrieved from http://www.playengland.org.uk/resources/design-for-play.aspx.

Shakespeare, T. (2014). Disability rights and wrongs revisited. Abingdon, UK: Routledge.

Spencer-Cavaliere, N., \& Watkinson, E. J. (2010). Inclusion understood from the perspectives of children with disability. Adapted Physical Activity Quarterly, 27, 275-93.

Sutton-Smith, B. 1997. The Ambiguity of Play. Cambridge, MA: Harvard University Press.

Taub, D. E., \& Greer, K. R. (2000). Physical Activity as a Normalizing Experience for School-Age Children with Physical Disabilities. Implications for Legitimation of Social Identity and Enhancement of Social Ties. Sport and Social Issues, 24, 395-414. 
Thomas, C. (2004). Developing the Social Relational in the Social Model of Disability: a theoretical agenda. In: C. Barnes, \& G. Mercer (Eds.), Implementing the Social Model of Disability: Theory and Research (pp. 32-47). Leeds, UK: Disability Press.

United Nations (2007). Convention on the Rights of Persons with Disabilities. Retrieved from: http:// www.un.org/disabilities/convention/conventionfull.shtml.

UNCRC Committee on the Rights of the Child (2016). Concluding Observations on the Fifth Periodic Report of the United Kingdom of Great Britain and Northern Ireland. DRAFT. Retrieved from: tbinternet.ohchr.org/Treaties/CRC/.../GBR/INT_CRC_IFN_GBR_21049_E.pdf.

Union of the Physically Impaired Against Segregation, UPIAS (1975). Fundamental Principles of Disability. [Statement]. Retrieved from:

http://www.disabilityarchive.leeds.ac.uk/authors_list.asp?AuthorID=174\&author_ name $=$ UPIAS.

Webb, R. (2003). Public Play Provision for Children with Disabilities. Sugradh, IRL: NDA

World Health Organisation (2011). World Report on Disability. Retrieved from: http://www.who.int/ disabilities/world_report/2011/en/.

World Health Organisation (2001). International Classification of Functioning Disability and Health. Geneva, $\mathrm{CH}$ : WHO.

Williams, R., Vogelsong, H., Green, G., \& Cordell, K. (2004). Outdoor Recreation Participation of People with Mobility Disabilities: "Selected Results of the National Survey of Recreation and the Environment. Journal of Park and Recreation Administration, 22, 85-101.

Woolley, H. (2013). Now Being Social: The Barrier of Designing Outdoor Play Spaces for Disabled Children. Children and Society, 27, 448-458. 